\title{
Output Adjust Assignment Algorithms about Electric Power Unit Transmission Congestion
}

\author{
Huaren ZHOU $^{1,2, a}$ Lili WANG ${ }^{3, b}$ \\ ${ }^{1}$ Institute of Sciences PLA Univ. of Sci. \& Tch Nanjing China 211101 \\ ${ }^{2}$ School of Economics and Management ,Nanjing University of Aeronautics and Astronautics, \\ Nanjing China 211106 \\ ${ }^{3}$ Naval Command College. Nanjing China,210016
}

a'Zhouzhu123123123@163.com

bWanglili81@gmail.com

KEYWORD: power block, multivariate linear regression model, adjust allocation algorithm ABSTRACT: output, transmission power and direction of each line about a network with a plurality of generating units and a number of main lines depends on the power grid structure and each generation unit. we get the approximate expressions of the output of each generator. When the transmission congestion appear, we study how to establish a safe and economical dispatching plan, and get output adjust allocation algorithm of the power unit when transmission congestion.

\section{Introduction}

Power from production to use has four big links, that is power, transmission, distribution and consumption, all is instantaneous. Assuming power market takes deals with scheduling integration mode.Suppose a network have a plurality of generating units and a number of main lines, output of each line depends on the power grid structure and each generation unit. The active power flow of each line is a safety limit on the absolute values of the limit value of relative safety, also has the certain margin (i.e, absolute trend value in case of emergency can exceed the limit value of the percentage of limit). If the active power flow exceed the limit of the absolute output value of each unit subjected to a distribution scheme, it is called the transmission congestion. When the transmission congestion appear, we want to study how to establish a safe and economical dispatching plan.

\section{Problem}

Suppose there are a grid with 8 generating units and 6 main lines, scheme 1 gives the active power flow corresponding to each unit and each line current output value, scheme of 2 33 gives around some experimental data 1 scheme, each line active power flow on the generator output approximate expression of these data to determine the trial. It is need to give the tidal current limit according to table 1 , examination by the output distribution plan would cause tr, ansmission congestion, and in the case of transmission congestion, according to the safety and economic principle, adjust the unit output allocation scheme, and gives the corresponding with the scheme of congestion cost. 
Table 1 The power line limit value and the relative safety margin

\begin{tabular}{|l|c|c|c|c|c|c|}
\hline Line & 1 & 2 & 3 & 4 & 5 & 6 \\
\hline Limit value & 165 & 150 & 160 & 155 & 132 & 162 \\
\hline Safety margin & $13 \%$ & $18 \%$ & $9 \%$ & $11 \%$ & $15 \%$ & $14 \%$ \\
\hline
\end{tabular}

According to table 1, we give the tidal current limit, examination by output distribution plan would cause the transmission congestion, and in the case of transmission congestion, according to the principle of safety and economy, we adjust the unit output allocation scheme, and gives the corresponding solution and the congestion charge, This plan is shown in Table 2.

Table 2 Plan

(unit: MW)

\begin{tabular}{|l|c|c|c|c|c|c|c|c|c|c|}
\hline $\begin{array}{l}\text { Line } \\
\text { Unit }\end{array}$ & 1 & 2 & 3 & 4 & 5 & 6 & 7 & $8,9,10$ & Output & $\begin{array}{c}\text { Corresponding } \\
\text { period of price }\end{array}$ \\
\hline 1 & 70 & 0 & 50 & 0 & 0 & 30 & 0 & 0 & 150 & 252 \\
\hline 2 & 30 & 0 & 20 & 8 & 15 & 6 & 0 & 0 & 79 & 300 \\
\hline 3 & 110 & 0 & 40 & 0 & 30 & 0 & 0 & 0 & 180 & 233 \\
\hline 4 & 55 & 5 & 10 & 10 & 10 & 9.5 & 0 & 0 & 99.5 & 302 \\
\hline 5 & 75 & 5 & 15 & 0 & 15 & 15 & 0 & 0 & 125 & 212 \\
\hline 6 & 95 & 0 & 10 & 20 & 0 & 15 & 0 & 0 & 140 & 252 \\
\hline 7 & 50 & 15 & 5 & 15 & 10 & 0 & 0 & 0 & 95 & 260 \\
\hline 8 & 70 & 0 & 20 & 0 & 20 & 0 & 3.9 & 0 & 113.9 & 303 \\
\hline
\end{tabular}

\section{Multiple linear regression model of generating unit power output}

we discuss active power flow of each line on the approximate expressions of the output of each generator. the assumption that the line active power flow is a linear function of the output of each generator, according to the 32 groups of experimental data in the problem, approximate expression of active power flow value on the output of each generation unit respectively is obtained by the regress command of Matlab as follows.

$$
\begin{aligned}
y_{1}= & 110.297+0.083 x_{1}+0.048 x_{2}+0.053 x_{3}+0.120 x_{4} \\
& -0.025 x_{5}+0.122 x_{6}+0.122 x_{7}-0.001 x_{8} \\
y_{2}= & 131.229-0.055 x_{1}+0.128 x_{2}+0.033 x_{4}+0.087 x_{5} \\
& -0.112 x_{6}-0.019 x_{7}+0.099 x_{8} \\
y_{3}= & 108.873+0.07 x_{1}-0.061 x_{2}+0.157 x_{3}+0.01 x_{4} \\
& -0.125 x_{5}+0.002 x_{6}+0.003 x_{7}+0.201 x_{8} \\
y_{4}= & 77.482-0.035 x_{1}-0.102 x_{2}+0.205 x_{3}-0.021 x_{4} \\
& -0.012 x_{5}+0.006 x_{6}+0.145 x_{7}+0.077 x_{8}
\end{aligned}
$$




$$
\begin{aligned}
y_{5}= & 132.975+0.001 x_{1}+0.243 x_{2}-0.065 x_{3}-0.041 x_{4} \\
& -0.065 x_{5}+0.07 x_{6}-0.004 x_{7}-0.009 x_{8} \\
y_{6}= & 120.663+0.238 x_{1}-0.06 x_{2}-0.078 x_{3}+0.093 x_{4} \\
& +0.047 x_{5}+0.166 x_{7}+0.001 x_{8}
\end{aligned}
$$

where $x_{i}(i=1,2, \mathrm{~L}, 8), y_{j}(j=1,2, \mathrm{~L}, 6)$

In order to test our optional three experiment schemes in the problem of testing the regression equation, This experiment schemes is shown in Table 3.

Table 3 Three experiment schemes

\begin{tabular}{|l|c|c|c|c|c|c|c|c|}
\hline $\begin{array}{l}\text { Project } \\
\backslash \text { Unit }\end{array}$ & 1 & 2 & 3 & 4 & 5 & 6 & 7 & 8 \\
\hline 3 & 158.77 & 73 & 180 & 80 & 125 & 125 & 81.1 & 90 \\
\hline 6 & 120 & 75.45 & 180 & 80 & 125 & 125 & 81.1 & 90 \\
\hline 13 & 120 & 73 & 180 & 75.857 & 125 & 125 & 81.1 & 90 \\
\hline
\end{tabular}

The current one period forecast load demand for 982.40MW, According to the output of the distribution of each unit is obtained with the use of the above, the approximate expression of multiple linear regression, we can obtain the line active power flow. The current theory of each unit output value is shown in table 4.

Table 4 The current theory of each unit output value

\begin{tabular}{|l|l|l|l|l|l|l|l|l|}
\hline Crew & 1 & 2 & 3 & 4 & 5 & 6 & 7 & 8 \\
\hline Output & 150 & 79 & 180 & 99.5 & 125 & 140 & 95 & 113.9 \\
\hline
\end{tabular}

Clearing price is now 303 yuan /MWH. Each line active power flow value is shown in table 5.

Table 5 Each line active power flow value

\begin{tabular}{|l|c|r|r|r|r|r|}
\hline Line & \multicolumn{1}{|c|}{1} & \multicolumn{1}{c|}{2} & \multicolumn{1}{c|}{3} & \multicolumn{1}{c|}{4} & \multicolumn{1}{c|}{5} & 6 \\
\hline $\begin{array}{l}\text { Active } \\
\text { power } \\
\text { flow }\end{array}$ & 173.2 & 141.01 & 150.93 & 120.92 & 136.83 & 168.53 \\
\hline $\begin{array}{l}\text { Limit } \\
\text { value }\end{array}$ & 165 & 150 & 160 & 155 & 132 & 162 \\
\hline $\begin{array}{l}\text { Safety } \\
\text { margin }\end{array}$ & $13 \%$ & $18 \%$ & $9 \%$ & $11 \%$ & $15 \%$ & $14 \%$ \\
\hline
\end{tabular}

As can be seen from the table 5, line 1, 5, 6 occur in transmission congestion, then we must implement the congestion management, first of all, we found that the line 1, 5, 6 although blocked.

\section{output adjusting allocation algorithm}

Aiming at the above problems, we propose output adjusting allocation algorithm about the following block transmission power unit, the algorithm is as follows:

Step1: The size of each unit is adjusted as far as possible in the theory of liquidation price under the condition of constant power output, and the elimination of transmission congestion is obtained. 
Step2: If the theory liquidation price is not changed in the constant situation, the transmission congestion is cannot eliminated, then according to the period of price higher than the clearing price size, first we change the period of price higher than the clearing price the smallest unit output, and then change the period of price higher than the clearing price small unit output;

Step3: According to Step1 and Step2, until the transmission congestion eliminate;

Step4: If unit output size can eliminate the transmission congestion in any case adjusting, we should try to avoid sliding gate.

After adjusting the output, the trend values is shown in table 6.

Table 6 The trend values after adjusting the output

\begin{tabular}{|l|l|l|l|l|l|l|l|l|}
\hline Crew & 1 & 2 & 3 & 4 & 5 & 6 & 7 & 8 \\
\hline Output & 117 & 86 & 220.3 & 79 & 115 & 110 & 102.1 & 117 \\
\hline
\end{tabular}

The current output value of each unit and each line active power flow value is shown in table 7.

Table $7 \quad$ Each line active power flow value

\begin{tabular}{|l|c|c|c|c|c|c|}
\hline Line & 1 & 2 & \multicolumn{1}{c|}{3} & \multicolumn{1}{c|}{4} & \multicolumn{1}{c|}{5} & 6 \\
\hline $\begin{array}{l}\text { Active } \\
\text { power } \\
\text { flow }\end{array}$ & 173.2 & 141.01 & 150.93 & 120.92 & 136.83 & 168.53 \\
\hline $\begin{array}{l}\text { Limit } \\
\text { value }\end{array}$ & 165 & 150 & 160 & 155 & 132 & 162 \\
\hline $\begin{array}{l}\text { Safety } \\
\text { margin }\end{array}$ & $13 \%$ & $18 \%$ & $9 \%$ & $11 \%$ & $15 \%$ & $14 \%$ \\
\hline
\end{tabular}

Clearing price is now 303 yuan / MWH, zero congestion cost is 0 .

\section{Conclusion}

With the development of power market, the electricity demand is rising sharply, the power resource is very tense, then how to make reasonable power resource scheduling becomes more and more important due to power outage loss.

so the adjustment method is especially important. the adjustment method in this paper is simple and Real time.

\section{References}

1 ZHOU Huaren,QIAN Yuehong,LIU Xiqiang,WU Ou.The Multiple Regression Analysis Model on Power Dispatch.ICEEP,2012

2 Huaren ZHOU, Yuehong, QIAN,ZeqingYAO,Zisen MAO. Research on Electric Power istribution Method.Applied Mechanics and Materials Vols.373-375(2013) pp2288-2291

3 Weiwei ZHANG.Load Economic Assigning Method for A Coal-fired Power Plant.TURBING TECHNOLOGY.2005.8(266-268)

4 Yunshan ZHOU. A Study on Optimal Algorithm of Real-time Load Dispatch Among Thermal Power Units.HUADIAN TECHNOLOGY.2008.6(22-26) 
5 Dakuo HE.Application of Genetic Algorithm on Economic Dispatch of Power Systems.Journal of System Simulation.2007.2(890-892) 